\title{
OFERTAS PÚBLICAS PRIMARIAS DE BONOS CORPORATIVOS EN EL PERÚ
}

\section{PUBLIC PRIMARY OFFERTS OF CORPORATE BONDS IN PERU}

\author{
Vladimir Rodríguez Cairo* \\ Docente Asociado de la Facultad de Ciencias Contables, UNMSM
}

[Recepción: Enero de 2010 / Conformidad: Marzo de 2010]

\section{RESUMEN}

El mercado de valores resulta muy atractivo para los inversionistas nacionales e internacionales, ya que este se caracteriza por canalizar flujos de fondos desde los agentes superavitarios (ofertantes de fondos prestables) hacia los agentes deficitarios (demandantes de fondos prestables), lo cual tiene como consecuencia un mayor nivel de inversión, generando a la vez crecimiento económico y de esta manera, el beneficio de todos los participantes. Las empresas se desenvuelven en un entorno financiero en el cual se exigen requisitos como solvencia, capital social, rentabilidad y trayectoria, lo cual resulta difícil de cumplirlos.

En estos tiempos, el financiamiento empresarial se circunscribe fundamentalmente al sistema bancario. Sin embargo, se requiere otra alternativa de financiamiento distinta a las tradicionales. Una alternativa fundamental es la emisión de bonos en el mercado primario de valores. Obtener financiamiento a través de este mercado resulta más eficiente para las empresas que recurrir a un crédito bancario, por el menor costo financiero que significa la emisión de bonos.

El artículo analiza los aspectos técnicos y legales de las Ofertas Públicas Primarias de Bonos Corporativos en el Perú y su implicancia en el acceso al financiamiento de las empresas al mercado primario de valores.

Palabras clave: Ofertas públicas primarias, mercado de valores, bonos corporativos, sistema financiero.

\begin{abstract}
The stock market is very attractive for international and national investors, as this channel is characterized by flows of funds from surplus agents (vendors of loanable funds) to the agent responsible (applicants for loanable funds), as a result a higher level of investment, while generating economic growth and thus the benefit of all participants. Companies operate in a financial environment in which requirements as required solvency capital, profitability and trajectory, making it difficult to meet them.

These days, business financing is limited mainly to the banking system. However, it requires different funding alternative to traditional. A fundamental choice is the issuance of bonds in the primary market for securities. Get financing through this market is more efficient for companies to resort to a bank loan, the lower financial cost which means the bond issue.

The article analyses the technical and legal aspects of the Primary Public Offerings of Corporate Bonds in Peru and its implication on access to corporate financing primary market values.
\end{abstract}

Key words: Primary public offerings, securities, corporate bonds, financial system.

* Magíster en Ciencias Económicas, UNMSM. Docente Asociado de la Facultad de Ciencias Contables - UNMSM. E-mail: vladirodriguezcairo@yahoo.es, vrodriguezc@unmsm.edu.pe 


\section{MERCADO DE VALORES}

El mercado de valores, parte integrante del sistema financiero ${ }^{1}$, reúne a múltiples agentes económicos (Estado, empresas, individuos y otros) que demandan y ofrecen fondos en los mercados financieros. El mercado financiero es el mecanismo o lugar a través del cual se interrelacionan agentes deficitarios y superavitarios, ofertantes y demandantes de activos financieros, dentro de un marco institucional constituido por reglas formales (leyes) e informales (costumbres) ${ }^{2}$; la interacción de la oferta y la demanda determinan los precios de los activos financieros ${ }^{3}$.

Fernández $\mathrm{Baca}^{4}$ sostiene que cuanto más grande y sólido sea el sistema financiero de un país o una región, mayores serán las oportunidades de inversión que se irán creando y explotando, lo que permitirá un crecimiento económico sostenido y la subsecuente mejora en los niveles de empleo y de vida. Si el sistema financiero es pequeño y débil, pocas serán las oportunidades de inversión que puedan ser aprovechadas adecuadamente, $y$ el país o región estará condenado al estancamiento y la pobreza.

\section{Estructura del mercado de valores}

La clasificación más usual del mercado de valores distingue al mercado primario y mercado secundario. Ambos son recíprocamente complementarios. La existencia de un mercado primario de valores, hace posible la presencia de un mercado secundario de valores.

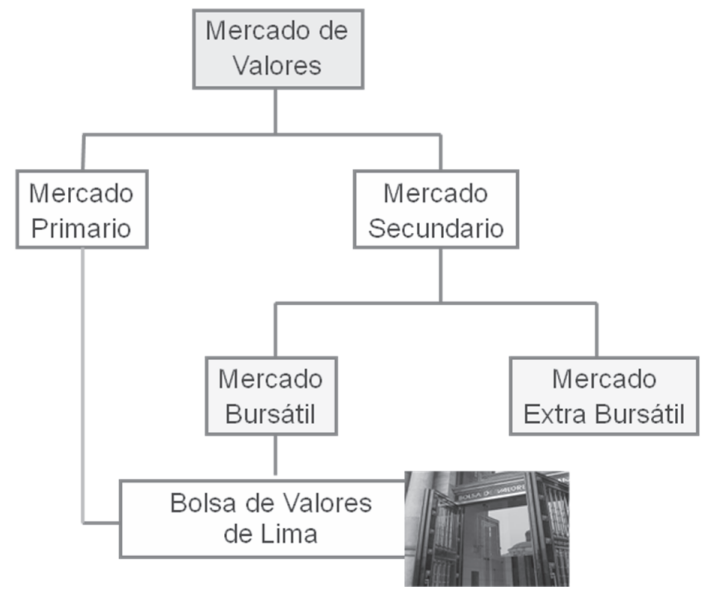

El mercado primario. Es aquel donde se efectúan ventas de valores recién emitidos a los compradores originales, motivo por el cual es denominado mercado de nuevas emisiones. Se llevan a cabo las ofertas públicas primarias de acciones, bonos e instrumentos

1 El sistema financiero está constituido por el conjunto de empresas bancarias, financieras y demás entidades de derecho público o derecho privado, debidamente autorizadas para operar en la intermediación financiera. La intermediación financiera es la actividad que realizan las empresas del sistema financiero consistente en la captación de fondos bajo cualquier modalidad, y su colocación mediante la realización de cualquiera de las operaciones permitidas por ley.

2 Douglass C. NORTH, Premio Nóbel en Economía en 1993, en su obra Instituciones, Cambio Institucional y Desempeño Económico, define las instituciones como las reglas de juego de una sociedad o más formalmente, son las limitaciones ideadas por el hombre que dan forma a la interacción humana. Por consiguiente, estructuran incentivos en el intercambio humano, sea político, social o económico. Asimismo, sostiene que las instituciones pueden ser formales e informales. Las instituciones formales son las reglas escritas en las leyes y reglamentos y son restricciones creadas por el hombre para resolver problemas específicos. Por otro lado, las instituciones informales son las reglas no escritas, que se van acumulando con el transcurso del tiempo y quedan registradas en los usos y costumbres.

3 Los activos financieros son los bonos, las acciones, entre otros. También se les denomina instrumentos financieros; son valores emitidos $\mathrm{u}$ ofrecidos por agentes económicos deficitarios a los agentes superavitarios y que se caracterizan por incorporar derechos sobre activos reales, tangibles e intangibles.

4 Fernández Baca, Jorge. Teoría y Política Monetaria. 1.a ed., Universidad del Pacífico, Lima 2008, p. 43. 
de corto plazo, asimismo, las emisiones privadas y las emisiones de los gobiernos.

El mercado secundario es aquel donde se efectúan transacciones que implican simples transferencias de activos financieros ya existentes y por lo tanto, el volumen de tales operaciones refleja el grado de liquidez del mercado. Este es un mercado de reventa, el cual permite nuevamente tener liquidez a los tenedores de valores.

La Bolsa de Valores es el principal mercado secundario de negociación. Son mercados organizados o debidamente reglamentados, cuyo objetivo es facilitar y fomentar la transacción o contratación de valores públicos y privados con la intermediación de agentes especializados. Es en definitiva, un órgano de centralización de la oferta y demanda de valores. La importancia de tal centralización para el desarrollo del mercado de valores, deriva de la mayor liquidez que ella origina.

\section{INSTRUMENTOS NEGOCIADOS EN EL MERCADO DE VALORES}

Los instrumentos del mercado de valores están constituidos por títulos valores ${ }^{5}$ y valores mobiliarios ${ }^{6}$ que son materia de negociación en dicho mercado.

En el Derecho Cambiario moderno se reconocen e identifican como género a los valores negociables y como especie a los en título o títulos valores $y$, a los valores elec- trónicos, que a la propia Ley del Mercado de Valores, D. Leg. N.o 861, los denomina "anotaciones en cuenta y registro" 7 .

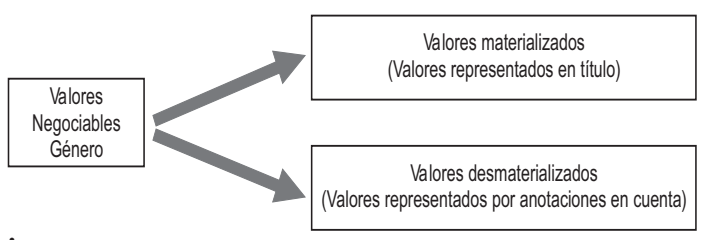

El actual artículo 1 de la Ley N.o 27287, Ley de Títulos Valores (LTV) alude a "valores materializados que representen o incorporen derechos patrimoniales" evidenciando el abandono a la concepción típicamente cartular, ya que pueden también existir títulos valores "desmaterializados".

La desmaterialización puede describirse "como el fenómeno de pérdida del soporte cartular por parte del valor incorporado, optando por la alternativa de su documentación por medios contables o informáticos". Con la desmaterialización o con la inmovilización de los valores se elimina las inexactitudes derivadas de procesos manuales y del trasiego físico de títulos; en igual forma, con la desmaterialización se disminuyen una serie de costos asociados al uso de papel ${ }^{9}$.

\section{OFERTAS PÚBLICAS PRIMARIAS}

En el mercado primario de valores, los emisores -que son los demandantes de fon-

5 El artículo 1 de la Ley de Títulos Valores (LTV) dispone que los valores materializados que representen o incorporen derechos patrimoniales, tendrán la calidad y efectos de título valor, cuando estén destinados a la circulación, siempre que reúnan los requisitos formales esenciales que, por medio de la ley, les corrresponda según la naturaleza. Si le faltare alguno de los requisitos formales esenciales que le corresponda, el documento no tendrá carácter de título valor. Es en definitiva, un documento sobre un derecho privado, cuyo ejercicio y cuya transmisión están condicionados a la posesión del documento.

6 El artículo 3 de La Ley del Mercado de Valores (LMV), D. Leg. N. ${ }^{8} 861$, define los valores mobiliarios como aquellos emitidos en forma masiva y libremente negociables que confieren a sus titulares derechos crediticios, dominiales o patrimoniales, o los de participación en el capital, el patrimonio o las utilidades del emisor.

7 Beaumont Callirgos Ricardo - Castellares Aguilar Rolando. Comentarios a la Nueva Ley de Títulos Valores. Editorial Gaceta Jurídica, Lima 2000, p. 8.

8 Beaumont Callirgos, Ricardo y Castellares Aguilar, Rolando. Obra citada, p. 43.

9 García Kilroy, Catiana. Apuntes para la Liquidación de Valores. San José, Costa Rica, 1998, p. 134. 
dos- ofrecen valores mobiliarios (acciones, bonos, certificados de depósito negociables, instrumentos de corto plazo, etc.) a los inversionistas, que son agentes superavitarios que se tienen excedente de fondos.

En ese sentido, la oferta pública de valores es una propuesta unilateral de carácter no receptiva, por estar dirigida a personas inde- terminadas y, por tanto, sin fuerza vinculatoria mientras no se produzca la aceptación; es un acto nominado, desde que existen normas que lo regulan, además de ser un acto comprendido dentro de los actos de comercio. Las ofertas públicas requieren la inscripción de los valores en el registro, salvo se trate de valores emitidos por el BCR y Gobierno Central.

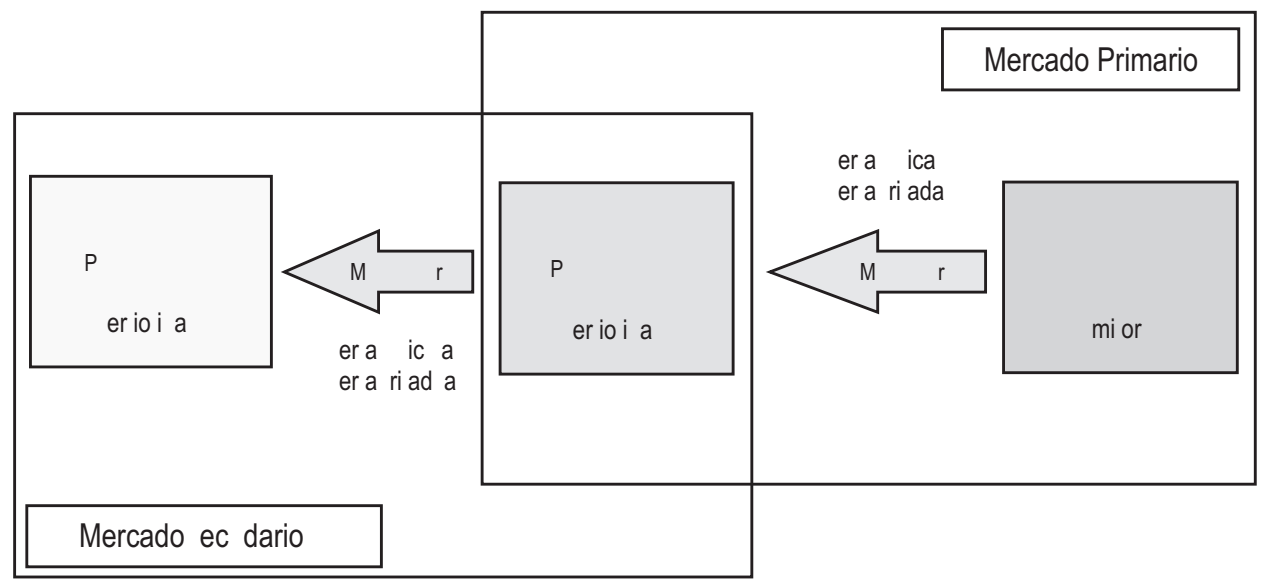

La Ley del Mercado de Valores (LMV), Decreto Legislativo N. ${ }^{\circ} 861$, artículo 4 establece que es oferta pública de valores mobiliarios la invitación, adecuadamente difundida que una o más personas naturales o jurídicas dirigen al público en general o a determinados segmentos de este, para realizar cualquier acto jurídico referido a la colocación, adquisición o disposición de valores. Esta definición contiene los siguientes elementos configurativos ${ }^{10}$ :

a) Invitación (manifestación de voluntad que se efectúa de modo directo o a través de terceros).

b) Emisor de los valores (persona jurídica de derecho público o privado. En la prác- tica, la sociedad anónima se constituye en la emisora por antonomasía).

c) Ofertante (agente de intermediación).

d) Destinatario de la invitación (público en general).

Si los valores son emitidos por primera vez, se trata de una Oferta Pública Primaria (OPP). Dos son los requisitos necesarios, según la ley, para una oferta pública primaria: nuevos valores (recién emitidos) y que los emita una persona jurídica. Según nuestra Ley del Mercado de Valores, la oferta pública primaria está referida a la oferta de nuevos valores que efectúan las personas jurídicas ${ }^{11}$.

En cuanto al objetivo de una OPP, se debe resaltar que esta sirve para obtener re-

10 Serra Puente-Arnao, Gerardo. El Mercado de Valores en el Perú. Editores Cultural Cusco S.A., Lima, 2002, pp. 227-228.

11 Como se puede notar, para nuestra legislación la característica fundamental de una OPP es la creación de nuevos valores, es decir, dar existencia a estos por primera vez, y que sean emitidos por entidades con personería jurídica. El adjetivo nuevo implica, en este contexto, que los valores mobiliarios no hayan sido objeto previo de intercambio. En consecuencia, la emisión de estos valores se concibe como un acto creador o primigenio y la oferta, generalmente, tiene como único propósito la colocación de los valores, esto es, la venta del emisor a un tercero y no otro acto jurídico. 
cursos de los agentes superavitarios (inversionistas), con la finalidad de utilizarlo en actividades productivas de la empresa, reestructurar deudas o para capital de trabajo.

\section{COLOCACIÓN ANUAL DE OFERTAS PÚBLICAS PRIMARIAS EN EL PERÚ}

En el Cuadro N.o 1, se puede apreciar las ofertas públicas primarias realizadas en nuestro país durante los años 2003-2008. Durante dicho período, los bonos corporativos representan el instrumento más utilizado por el sector empresarial como alternativa de financiamiento. Es así que en el año 2008, el monto colocado a través de bonos corporati- vos (1.823.040) representa el $61.55 \%$ del total colocado en soles (2.961.820). Para este mismo año, el monto colocado en dólares (85.229) representa el $22.95 \%$ del total del monto colocado en dólares (371.213).

En el mismo período, solo se emitieron acciones en el año 2007. El monto colocado en dólares fue de US\$ 13.462 dólares, representando el $0.45 \%$ del monto total colocado en dólares. De igual manera, se emitió acciones por el monto de $S / .64 .621$ soles, representado el $1.95 \%$ del monto total colocado en soles. Esto demuestra que las empresas en nuestro país prefieren la deuda antes que compartir la dirección de la empresa ${ }^{12}$.

En los últimos años se ha observado un importante uso del mercado de valores por

Cuadro N.o 1. Colocación Anual de Ofertas Públicas Primarias 2003-2008 (en miles de unidades monetarias)

\begin{tabular}{|c|c|c|c|c|c|c|c|c|c|c|c|c|}
\hline \multirow{2}{*}{ Tipo de instrumento } & \multicolumn{2}{|c|}{2003} & \multicolumn{2}{|c|}{2004} & \multicolumn{2}{|c|}{2005} & \multicolumn{2}{|c|}{2006} & \multicolumn{2}{|c|}{2007} & \multicolumn{2}{|c|}{2008} \\
\hline & US\$ & $\mathbf{S} /$. & US\$ & $\mathbf{S} /$. & US\$ & S/. & US\$ & S/. & US\$ & S/. & US\$ & $\mathbf{S} /$. \\
\hline A. Acciones & - & - & - & - & - & - & - & - & 13.462 & 64.621 & - & - \\
\hline B. Bonos & & & & & & & & & & & & \\
\hline - B. Corporativos & 395.847 & 1.169 .935 & 430.551 & 871.160 & 296.098 & 1.158 .295 & 478.000 & 2.093 .030 & 192.507 & 2.246 .215 & 85.229 & 1.823 .040 \\
\hline - B. Arrendamiento financiero & 137.840 & 45.000 & 35.036 & - & 114.000 & - & 61.000 & - & 94.625 & 50.000 & 158.342 & 354.640 \\
\hline - B. Estructurados & - & - & 20.000 & - & - & - & - & - & - & - & - & - \\
\hline - B. Hipotecarios & - & - & 25.000 & - & 15.000 & - & - & - & 15.000 & - & - & - \\
\hline - B. Subordinados & 45.000 & - & - & - & - & - & - & - & 40.000 & 160.000 & 50.000 & 235.000 \\
\hline - B. De titulización & 91.400 & - & 142.935 & 52.200 & 241.000 & 80.000 & 50.000 & 210.000 & 40.000 & 231.000 & & 95.000 \\
\hline C. Instrumentos de corto plazo & 205.500 & 345.000 & 108.760 & 115.000 & 162.589 & 449.805 & 134.503 & 131.665 & 200.389 & 201.180 & 77.660 & 209.140 \\
\hline D. Certificados de depósito negociables & - & 441.700 & 3.000 & 604.870 & - & 439.009 & 13.000 & 273.017 & 5.000 & 365.000 & & 245.000 \\
\hline Colocaciones de oferta pública & 875.587 & 2.001 .635 & 765.282 & 1.643 .230 & 828.687 & 2.127 .109 & 736.503 & 2.707 .712 & 600.983 & 3.318 .016 & 371.231 & 2.961.820 \\
\hline
\end{tabular}

Fuente : CONASEV - Gerencia de Investigación y Desarrollo.

12 Pese a que la emisión de acciones permite obtener una mejor posición financiera y no tienen fecha fija de vencimiento, las empresas son renuentes a recurrir a esta alternativa de financiamiento, sobre todo porque emitir acciones extiende los derechos de voto o control. Tal situación explica la resistencia de los propietarios hacia la colocación de acciones en el mercado, debido al temor de la probable pérdida de control. 
el sector privado, aunque sin llegar aún a los niveles alcanzados por los principales mercados de la región.

Tal como se observa en el Cuadro N.o 1 , la colocación anual de las ofertas públicas primarias tuvo un crecimiento durante el período 2004-2007. En el año 2004, el monto total colocado fue de US\$ 1248 millones de dólares y el año 2007 US\$ 1670 millones.

Durante el año 2002, las 61 emisiones de OPP inscritas acumularon un monto equivalente a US\$ 1217.8 millones, $89.1 \%$ del total del año 2001. En el mismo lapso el monto colocado alcanzó los US\$ 828 millones.

En el año 2003, las emisiones de oferta pública primaria inscritas en el RPMV, sumaron US\$ 1736.0 millones, lo que representó un incremento de $42.8 \%$ respecto al año 2003; el monto colocado alcanzó en el mismo período los US\$ 1451 millones, que representó un incrementó de $75.3 \%$ con relación al año anterior.

Para el año 2004, las emisiones de oferta pública primaria inscritas en el RPMV, sumaron US\$ 2059.5 millones, lo que representó el 118.6\% del total del año 2003; el monto colocado alcanzó en el mismo período los US\$ 1248 millones, 85.9\% del total del año 2003.

A diciembre del año 2005, el monto colocado alcanzó los US\$ 1474 millones de dólares.
El año 2006, el monto colocado alcanzó los US\$ 1565 millones y durante el año 2007, el monto colocado alcanzó los US\$ 1670 millones de dólares.

\section{BONOS CORPORATIVOS COMO ALTERNATIVA DE FINANCIAMIENTO EN EL PERÚ}

Los bonos son también conocidos como obligaciones $^{13}$. Son instrumentos financieros de renta fija, emitidos a largo plazo por una empresa, gobierno u organismo público, con un determinado tipo de interés y fecha previstas de pago de los intereses y reembolso del principal ${ }^{14}$.

Mediante un bono, el prestatario (agente deficitario) acuerda o se compromete a pagar al prestamista (inversionista) una tasa cupón periódicamente (trimestral, semestral o anual) y el valor nominal al vencimiento. El destino de los recursos captados se utiliza para financiar parte de sus activos fijos, reestructurar sus deudas o capital de trabajo.

Para Enrique Elías ${ }^{15}$, son tres los caracteres esenciales de las obligaciones: a) cada obligación representa una parte alicuanta (o sea, no necesariamente alícuota) de un crédito; b) su naturaleza de valor mobiliario, no siempre representado por un título; c) es un valor que confiere al titular un conjunto de derechos y obligaciones especiales que le otorgan un estatus de obligacionista.

13 Noriega Nairn Fernando, La Bolsa de Valores, Instituciones e Instrumentos del Mercado de Valores Peruano. 1. a ed., Universidad de San Martín de Porres, Lima 1998, pp. 93-103.

14 El artículo 263.1 de la Ley de Títulos Valores, estipula que los valores representativos de obligaciones incorporan una parte alícuota o alicuanta de un crédito colectivo concedido a favor del emisor, quien mediante su emisión y colocación reconoce deudas a favor de sus tenedores. El artículo 263.2 establece que cada emisión puede ser realizada en una o varias series, numeradas. Además, precisa que los valores que representan las obligaciones pueden ser solo nominativos o al portador. A su vez, el artículo 86 de la Ley del Mercado de Valores, define a los bonos como la oferta pública de valores representativos de deuda a plazo mayor a un año.

15 Elías Enrique. Derecho Societario Peruano. Editora Normas Legales S.A.C., 1019 páginas, Trujillo, 1999. 


\section{Características de un bono}

- El plazo de vencimiento. Es el tiempo durante el cual el emisor promete cumplir las condiciones de la obligación ${ }^{16}$.

- El vencimiento. Se refiere al día en que la deuda dejará de existir y que el emisor amortizará el bono pagando la cantidad prestada (valor de vencimiento del bono: $\mathrm{M}$ ) además de los intereses pacta$\operatorname{dos}(\mathrm{C})$.

- El principal $(P)$ de un bono (denominado también valor a la par, valor de vencimiento, valor de rescate). Es la cantidad que el emisor acuerda pagar al tenedor del bono (inversionista u obligacionista) a la fecha de vencimiento.

- La tasa cupón (c). Es la tasa de interés (expresada en tanto por uno o en tanto por ciento) que el emisor acuerda pagar al inversionista en cada período establecido en el contrato, pudiendo ser bimestral, trimestral, semestral o anual.

- El cupón (C). Es la cantidad de intereses pagado a los inversionistas durante el plazo del bono. Se expresa en unidades monetarias. La tasa cupón, cuando es multiplicada por el principal del bono, proporciona la cantidad de unidades monetarias del cupón.

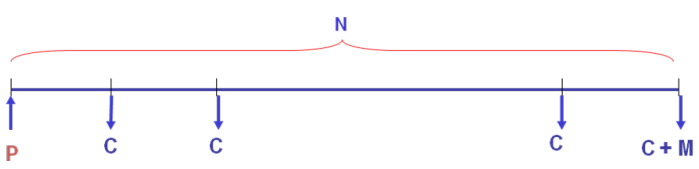

Donde:

$\mathrm{N}$ : Plazo (período de redención) del bono.

$P$ : Principal o precio de venta.

C: Intereses (cupones).
M: Valor nominal, a ser honrado por la empresa a su vencimiento.

\section{Tipos de bonos}

Existen diversos tipos de bonos, entre los cuales se pueden señalar los siguientes:

Los bonos del tesoro. Emitidos por el tesoro público. Son instrumentos que permiten financiar operaciones del Gobierno.

Los bonos corporativos. Emitidos por las empresas para captar fondos que le permi$\tan$ financiar sus operaciones y proyectos de inversión. Resultan actractivos para las empresas porque no necesariamente están respaldados por garantías específicas. Los emisores tienen la posibilidad de diseñarlos de acuerdo con las características que se ajusten y convengan a sus propios requerimientos de financiamiento y en función a un estudio de demanda de este tipo de instrumento.

Los bonos de arrendamiento financiero. Emitidos por instituciones bancarias, financieras y de arrendamiento financiero, con la finalidad de captar fondos destinados a comprar activos fijos para emplearlos en arrendamiento financiero. Tienen como límite los montos fijados para las operaciones pasivas de las entidades bancarias y financieras.

Los bonos estructurados. Son parte de los llamados instrumentos de inversión estructurados, los cuales son deudas que representan una renta variable a su tenedor. La rentabilidad ofrecida se deriva de la rentabilidad futura de un portafolio de otros activos financieros.

Los bonos subordinados. Solo los bancos y las empresas financieras los emiten a plazos

16 En el ámbito jurídico, se entiende por obligación, a la relación jurídica entre dos sujetos, acreedor y deudor, por el cual, se constriñe al deudor a dar, hacer, no hacer algo; es decir, es la potestad del acreedor de exigir al deudor el cumplimiento de la obligación. 
no menores de cinco años, sin opción a garantizarlos ni procede su pago antes del vencimiento ni su rescate por sorteo.

Los bonos convertibles. Emisión de bonos por el cual, el tenedor del bono tiene el derecho o la opción de intercambiar la obligación por una cantidad específica de acciones comunes.

\section{PARTICIPANTES EN UNA OFERTA PÚBLICA PRIMARIA DE BONOS CORPORATIVOS}

Respecto a los agentes intervinientes en una emisión, podemos decir que los bonos son emitidos por el deudor (cualquier persona jurídica del sector público o privado y no solo por las sociedades anónimas como lo disponía la ley anterior); que pueden ser adquiridos por los inversionistas, a quienes se les informa de las condiciones del endeudamiento y de la forma de pago a través de los prospectos informativos y documentación complementaria referida a la persona jurídica deudora y característica de las obligaciones. El proceso de información es controlado por la CONASEV, sin que ello signifique que dicha autoridad recomiende o garantice el buen fin de la inversión ${ }^{17}$.

Los principales participantes en una oferta pública primaria de bonos corporativos son los siguientes:

1. Emisor. Entidad privada que emite bonos corporativos y los ofrece al público en general o a un sector determinado de éste. Las empresas emisoras son agentes deficitarios que requieren fondos, sea para financiar un nuevo proyecto de inversión, para ampliar su capacidad de producción o para reestructurar sus pasivos con un financiamiento, generalmente de largo plazo.

La importancia de las empresas emisoras radica en que constituyen la fuente del mercado primario (emisión primaria de valores) que da origen al mercado de capitales, al generar nuevas ofertas de valores.

Durante el período 2003-2008, nuestro mercado se caracterizó por el reducido número de empresas emisoras de bonos corporativos (en total 48 empresas), de las cuales, solo 4 fueron realizadas por medianas empresas ${ }^{18}$.

Con relación a la clasificación de las empresas, el sistema financiero viene empleando categorías que en promedio fluctúan entre los valores siguientes ${ }^{19}$ :

- Microempresa $=$ ventas anuales menores a US\$ 50000.

- Pequeña empresa $=$ ventas anuales mayores a US \$ 50000 y menores de US \$ 1 millón.

- Mediana empresa $=$ ventas anuales mayores a US \$ 1 millón y menores a US \$ 30 millones.

- Gran empresa = ventas anuales mayores a US \$ 30 millones.

2. Obligacionistas. Son los agentes superavitarios o inversionistas (individuales o institucionales) cuyo principal objetivo es obtener una rentabilidad para el excedente de recursos financieros que tienen en su poder. Se les denomina también bonistas, tenedores del bono o demandante

17 Castellares, Rolando; Díaz, Enrique; Rocca, Lilian; Vargas, Julio. El ABC del Mercado de Capitales. Universidad San Ignacio de Loyola, Lima, 1998, p. 115.

18 Véase cuadro N. ${ }^{\circ}$ 2: Colocación anual de bonos corporativos por emisor y tipo de monedas 2003- 2008.

19 Ministerio de Economía y Finanzas. Resultado de Consulta Ciudadana: Acceso a Financiamiento a través del Mercado de Valores; 116 pp, Lima 23 de mayo de 2001, p. 25. 
de activos financieros. Los principales demandantes de valores mobiliarios son los inversionistas institucionales como las AFP, Empresas de Seguros, Agentes de Intermediación, Fondos Mutuos, Fondos de Inversión, Bancos, Financieras.

3. Representante de los obligacionistas. En el caso de la emisión de bonos, se requiere que la empresa emisora designe un representante de los obligacionistas. Solo las empresas bancarias, financieras o las sociedades agentes podrán ser designadas como representantes ${ }^{20}$. La actual LGS - Ley N.o 26887, emplea la misma denominación que la LMV - D.Leg. N.o 861 "representante de obligacionistas" a diferencia de la anterior LGS que se refería a ellos con el nombre de fideicomisarios.

Este representante es el intermediario exclusivo y excluyente, entre la sociedad emisora y el sindicato de obligacionistas, siendo su principal finalidad velar por el cumplimiento de los términos de la emisión. Su función está determinada por la ley y por el contrato respectivo; interactúa y colabora con la asamblea, a fin de cumplir debidamente con la representación del sindicato y con sus funciones de gestión en beneficio del mismo. La primera función del representante de los obligacionistas, será la de suscribir el contrato de emisión a nombre de los futuros titulares de bonos, para luego convocar a la asamblea de obligacionistas cuando se suscriba el 50\% de la emisión.
Convocada la asamblea, esta aprobará o desaprobará su gestión, ratificando o designando su reemplazante a dicho cargo, de conformidad con lo establecido por la LGS.

4. Estructurador. Entidad encargada de la dirección de la oferta pública, esto es de realizar el estudio de la emisión y colocación de bonos. Asimismo, diseña o estructura las características de la emisión de los bonos. Pueden desempeñarse como tales los agentes de intermediación y bancos de inversión regulados por la Ley General del Sistema Financiero y de Seguros, así como las entidades que determine CONASEV ${ }^{21}$.

Cabe resaltar que la Entidad Estructuradora será responsable, en todos los casos, de velar porque el emisor y/o la persona que corresponda, presente la información y documentación pertinente al momento de la inscripción de la Oferta Pública Primaria de Valores.

5. Agente de intermediación. Realiza la invitación a los inversionistas para que adquieran los bonos corporativos objeto de la oferta pública. El artículo 50 de la Ley del Mercado de Valores, establece que en las ofertas públicas de valores es obligatoria la intervención de un agente de intermediación, salvo en los casos contemplados en los artículos 63 y 127 y en la colocación primaria de certificados de participación de los fondos mutuos y los fondos de inversión.

20 El artículo 87 de la LMV dispone que toda emisión de bonos, incluidos los BAF, requiere de la designación del representante de los obligacionistas, excepto cuando las emisiones se encuentren dirigidas a inversionistas institucionales bajo las condiciones que CONASEV establezca. Puede ser designado como representante de los obligacionistas cualquier persona natural o jurídica que cumpla con los requisitos establecidos por CONASEV mediante norma de carácter general. En cualquier caso, no podrá designarse como representante de los obligacionistas al emisor, ni a las personas con las que éste tenga vinculación conforme a las normas que apruebe CONASEV.

21 El artículo 56 de la LMV, relacionado al contenido del prospecto informativo, establece que debe contener entre otros aspectos, nombre y firma de las personas responsables de la elaboración del prospecto informativo: entidad estructuradora o su representante. El Prospecto Informativo contiene datos necesarios para que los inversionistas tomen sus decisiones de comprar o no el valor mobiliario. 
6. Clasificadora de riesgo. Emiten opinión acerca de la situación financiera de la empresa emisora y del riesgo o calidad de la emisión ${ }^{22}$.

Los criterios que se toman en cuenta para la clasificación de riesgos son: 1) la solvencia del emisor, 2) la variabilidad de los resultados económicos del emisor, 3 ) la probabilidad que las obligaciones puestas en circulación por el emisor resulten impagas, 4) las características del valor, 5) la liquidez del valor, 6) la información disponible a los fines de la clasificación. La LMV establece que la clasificación de riesgo solo puede ser desarrollada por las denominadas Clasificadoras de Riesgo, cuyo control y supervisión está a cargo de CONASEV. Actualmente, operan en nuestro país las empresas clasificadoras de riesgo: APOYO Y ASOCIADOS INTERNACIONALES S.A.C. CLASIFICADORA DE RIESGO, CLASS \& ASOCIADOS S.A. CLASIFICADORA DE RIESGO, EQUILIBRIUM CLASIFICADORA DE RIESGO S.A. Y CLASIFICADORA DE RIESGO PACIFIC CREDIT RATING SAC.

7. Ente regulador. La regulación del mercado de valores por parte del Estado está a cargo de CONASEV (Comisión Nacional Supervisora de Empresas y Valores). A diferencia de algunos otros países, el ente regulador en nuestro país está especializado únicamente en el mercado de valores y no tiene participación en la supervisión de otros mercados como el bancario o el de seguros.
CONASEV es una institución pública del Sector Economía cuya finalidad es promover el mercado de valores, velar por la transparencia, la correcta formación de precios y la protección de los inversionistas, procurando la difusión de toda la información necesaria para la adopción de las decisiones financieras relativas a los valores y la igualdad de trato a todos ellos. Asimismo, se encarga de dictar las normas que regulan el mercado de valores, así como de supervisar y controlar las diferentes instituciones que participan en dicho mercado.

8. CAVALI ICLV. Es una sociedad anónima, cuya finalidad es registrar valores que han sido convertidos en registros computarizados o anotaciones en cuenta (desmaterializados) y realizar la liquidación de operaciones efectuadas en la Bolsa de Valores de Lima.

\section{PROCEDIMIENTO PARA LA COLOCACIÓN DE OFERTAS PÚBLICAS PRIMARIAS DE BONOS CORPORATIVOS}

En nuestro país, el proceso de emisión de bonos corporativos se efectúa a través de tres etapas $^{23}$ :

1. Preparación de la emisión. En esta etapa, la empresa elige el banco que actuará como estructurador y colocador de los instrumentos de deuda. Una vez elegido el estructurador, se elabora el Prospecto Marco que contiene las características

22 Según el artículo 280 de la LMV, las personas jurídicas que emitan por oferta pública valores representativos de deuda deberán contratar los servicios de por lo menos dos clasificadoras, independientes entre sí, para que efectúen la clasificación permanente de dichos valores, lo que se denomina en la doctrina como clasificación obligatoria.

23 Reglamento de Oferta Pública y de Venta de Valores Mobiliarios (Res. Conasev N. ${ }^{\circ}$ 141-1998-EF/94.10; Res. Conasev N. ${ }^{\circ}$ 107-2003-EF/94.10). Texto Único Ordenado de la Ley del Mercado de Valores (D.S. N.॰ 093-2002); "La Financiación de PYMES y los Mercados de Valores", Farah Manssur - Estudio Echecopar; diarios diversos. 
generales de la emisión (monto, moneda, plazo, etc.) y el Contrato de Emisión que reúne los derechos y los deberes del emisor y del representante de los obligacionistas.

2. Oferta pública primaria de bonos corporativos. Para realizar la oferta pública de sus valores, la empresa debe contratar dos clasificadoras de riesgo, solicitar el registro del Prospecto Marco en el Registro Público del Mercado de Valores de la CONASEV, inscribir el bono en la Bolsa de Valores de Lima (BVL), entre otras tareas.

3. Mantenimiento del a oferta pública primaria de bonos corporativos. La empresa emisora debe realizar pagos mensuales a CONASEV, la BVL y CAVALI. Asimismo, debe retribuir anualmente al representante de los obligacionistas quien debe informar a la Conasev sobre la evolución de las condiciones de la emisión.

El proceso de colocación de bonos corporativos se da cuando los agentes deficitarios requieren fondos para financiar sus proyectos de inversión y no les resulta conveniente o suficiente tomarlos del sistema bancario, entonces recurren a la emisión de valores mobiliarios y captan así los recursos necesarios directamente de los agentes superavitarios.

Los bonos corporativos son colocados fundamentalmente por bancos de inversión. Un banco de inversión ${ }^{24}$ es el intermediario directo entre la empresa emisora y el inversionista que desea adquirir valores ofertados. El banco de inversión no solo realiza la oferta de títulos de empresas a inversionistas directos, sino que realiza un proceso especializado de asesoría integral, que va desde la defini- ción del tipo de instrumento más conveniente para la empresa emisora, hasta el servicio post-venta, que busca que el título emitido posea liquidez en el mercado y cobertura de información en forma permanente.

El artículo 294 de la Ley General del Sistema Financiero y del Sistema de Seguros Ley N.o 26702, establece que los bancos de inversión están facultados para efectuar las siguientes operaciones y servicios:

\section{Numeral 4: Originar, estructurar, distri- buir y suscribir transitoriamente, en todo o en parte emisiones primarias de valo- res en el mercado doméstico o externo para su posterior colocación al público, con la facultad de otorgar al emisor una garantía total o parcial de la colocación.}

La responsabilidad fundamental de un banco de inversión consiste en asesorar al agente deficitario o emisor y determinar el financiamiento más adecuado a sus necesidades.

El procedimiento para colocación de ofertas públicas primarias bonos corporativos, contempla los pasos siguientes:

1. El agente deficitario (demandante de fondos prestables) se enfrenta fundamentalmente a dos alternativas de financiamiento: recurrir al sistema bancario o al mercado de valores. Una vez que el emisor decide obtener financiamiento a través del mercado de valores, sea mediante bonos o acciones, debe contratar los servicios de un estructurador para realizar la Oferta Pública Primaria de Valores.

2. El estructurador se encarga de diseñar la emisión o programa de emisión de los bonos corporativos. Este diseño implica realizar un análisis financiero, de sensibilidad y riesgos del mercado y del emisor;

24 López, Rafael; Sousa, Lorenzo. Banca de Inversión en el Perú. Publicaciones Universidad de Piura, Piura, 1996, p. 29. 
definir la estructura de la emisión (montos, plazos, amortizaciones, tasas, entre otras características); brindar asesoría en la elaboración de las Actas de Junta de Accionistas, contrato de colocación, minuta de emisión, solicitud para CONASEV, etc. Las sociedades agentes de bolsa, los bancos o cualquier otra entidad que determine CONASEV, incluso el mismo emisor, puede actuar como estructurador.

3. Si el emisor ofrece instrumentos de deuda en el mercado primario, como por ejemplo bonos corporativos, debe contratar los servicios de por lo menos dos (2) empresas clasificadoras de riesgo independientes entre sí para que efectúen la clasificación permanente de dichos valores. De acuerdo con lo establecido en nuestra legislación, en los demás casos, la clasificación es facultativa. Como parte de su labor, la clasificadora se encarga de realizar el análisis financiero del emisor y de la emisión (calce de plazos, endeudamiento económico, estrategia empresarial, perspectivas del negocio, posicionamiento en el mercado, etc.). Concluido su análisis emite una opinión, expresada en categorías, sobre la capacidad del emisor para cumplir o no sus obligaciones (con los inversionistas) en las condiciones y plazos establecidos en el contrato de emisión ${ }^{25}$.
4. Una vez estructurada la emisión o programa de emisión, el emisor remite a CONASEV la información y documentación solicitando su inscripción en el Registro Público del Mercado de Valores (RPMV).

El artículo 18 de la LMV, establece que la inscripción de un valor o de un programa de emisión de valores en el RPMV se debe presentar a CONASEV con los documentos donde conste sus características, las del emisor y en su caso, los derechos y obligaciones de sus titulares $^{26}$.

5. CONASEV revisa el expediente y si este cumple con todos los requisitos autoriza la inscripción de la emisión o programa de emisión en el RPMV ${ }^{27}$. Por su parte, el artículo 54 de la LMV establece que para la inscripción de un valor que será objeto de oferta pública primaria en el Registro Público del Mercado de Valores (RPMV), el emisor deberá presentar a CONASEV lo siguiente:

a) Comunicación del representante legal del emisor, con el contenido y formalidades que CONASEV establezca.

b) Documentos referentes al acuerdo de emisión, donde consten las características de los valores a ser emitidos y los deberes y derechos de sus titulares.

c) El proyecto de prospecto informativo sobre la emisión.

25 El análisis de la capacidad de pago de la empresa emisora de obligaciones, se resume en una clasificación de riesgo que se expresa mediante una simbología con significados determinados establecida por CONASEV.

26 La realización de una oferta pública de venta de valores en Perú por parte de una empresa, debe cumplir determinados requisitos establecidos en el artículo 54 de la LMV. Para la inscripción de un valor que será objeto de oferta pública primaria en el Registro Público del Mercado de Valores (RPMV), el emisor deberá presentar a CONASEV lo siguiente: comunicación del representante legal de emisor a CONASEV, documentos referentes al acuerdo de emisión, el proyecto de prospecto informativo sobre la emisión, estados financieros auditados del emisor, clasificación de Riesgo.

27 Es importante señalar que de acuerdo con el artículo 22 de la LMV, la inscripción de un valor en el RPMV no implica la certificación sobre su bondad, la solvencia del emisor, ni sobre los riesgos del valor o de la oferta. En consecuencia, CONASEV no está autorizada para analizar los valores materia de oferta pública, ni opinar sobre la misma, su labor se limita en este aspecto, únicamente a observar el cumplimiento de las normas sobre la inscripción en el RPMV y la divulgación de hechos de importancia. 
d) Los estados financieros auditados del emisor, con sus notas explicativas y el respectivo dictamen, correspondientes a los dos últimos años, cuando el período de constitución lo permita.

e) Obtener la clasificación de riesgo cuando corresponda. Con la finalidad de disminuir en parte el riesgo que una OPP puede conllevar para los potenciales inversionistas, nuestra legislación ha incorporado la clasificación del riesgo, pero tan solo con relación a la emisión de bonos.

6. Una vez autorizada la inscripción, el emisor transfiere los valores al agente de intermediación. Si se trata de acciones, el agente de intermediación se convierte en accionista del emisor, condición que se mantiene hasta la colocación en el mercado. De la misma forma, si se trata de bonos, el agente de intermediación se convierte en acreedor de la empresa emisora.

7. El agente de intermediación -que también puede actuar como estructurador- prefinancia al emisor descontando la comisión que cobra por la operación, cuando se trata de la colocación en firme.

8. El agente de intermediación coloca o vende los valores a los inversionistas (individuales e institucionales). La colocación puede hacerse bajo las modalidades de underwriting en firme y no en firme ${ }^{28}$. La característica esencial del contrato de underwriting es que se contrae a valores de emisión primaria. La finalidad del underwriting para el agente de intermediación es obtener la mayor ganancia al comprar y vender, los valores emitidos por una empresa y para el emisor, permite tener acceso al mercado de capitales con el fin de satisfacer sus necesidades de financiamiento, de una manera rápida y segura.

Según Arias-Schreiber ${ }^{29}$, el contrato de underwriting en firme es aquel por el cual una entidad financiera suscribe la totalidad o una parte de los títulos emitidos por la sociedad emisora, entregando en ese momento el monto de dicha suscripción a la sociedad emisora, quien no tendrá que preocuparse de la estrategia de colocación de dichos títulos. Farina sostiene que esta modalidad ${ }^{30}$, cuando el underwriter ha adquirido obligaciones negociables, este se convierte en acreedor de la emisora ${ }^{31}$.

Ulises Montoya ${ }^{32}$ afirma que en la colocación no en firme el agente de intermediación procura la colocación en el mercado de los títulos, pero por cuenta y riesgo del emisor. En este caso, si no hay conjuntamente una prefinanciación, estamos ante un corretaje. Juan Farina sostiene que en esta modalidad, el underwriter solo prefinancia la emisión de los títulos, obligándose a procurar la colocación en

28 En nuestro país, las colocaciones se realizan bajo la modalidad de underwriting en firme. Según Ulises Montoya, el underwriting se origina a fines del siglo XVIII en el derecho anglosajón. Siendo su antecedente más antiguo el seguro marítimo en el que se asumía el riesgo del viaje. Un siglo después, con el crecimiento de la empresa industrial, surgió la conveniencia de recurrir al crédito del público, es así que existían empresas especializadas que se dedicaban a la promoción de títulos valores y a la colocación de los mismos entre el público inversionista.

29 Arias-Schreiber Pezet, Max; Gutierrez Camacho, Walter. La Técnica Contractual. Tomo III, Editorial Gaceta Jurídica, Lima 2001, p. 125.

30 Farina Juan M. Contratos Comerciales Modernos. 2. ${ }^{a}$ ed., Editorial Astrea, Ciudad de Buenos Aires, 830 pp., 1997, p. 520.

31 Cuando se trata de emisión de acciones, como quiera que el agente de intermediación adquiere dichos valores a su nombre, se convierte en accionista de la empresa emisora, condición que mantendrá hasta la colocación de estos en el mercado.

32 Montoya Manfredi, Ulises; Montoya Alberti, Ulises; Montoya Alberti, Hernando. Comentarios a la Ley de Títulos Valores. Editora Jurídica Grijley, Lima, 2005. 
el mercado con el mayor esfuerzo, pero por cuenta del emisor, quien asume los riesgos de la operación. De tal forma, la prefinanciación reviste el carácter en un mutuo comercial y la obligación de procurar la colocación adquiere la naturaleza de un mandato.

9. Los inversionistas (individuales e institucionales) adquieren los bonos corporativos y el agente de intermediación recibe los fondos producto de la venta de los valores ${ }^{33}$.

10. El emisor procede al pago de los intereses y del principal de acuerdo con la periodicidad y condiciones establecidas en el prospecto informativo. Dichos pagos los puede realizar directamente o a través de CAVALI $^{34}$.

11. Cuando se trata de una emisión de bonos, el emisor debe designar a un representante de los obligacionistas. Este representante es un intermediario directo y excluyente, entre la sociedad emisora y el sindicato de obligacionistas, tienen como finalidad velar por el cumplimiento de los términos de la emisión.

A continuación, se presenta un esquema con los once pasos que debe seguir una empresa emisora que realice una Oferta Pública Primaria de Bonos Corporativos en el Perú.

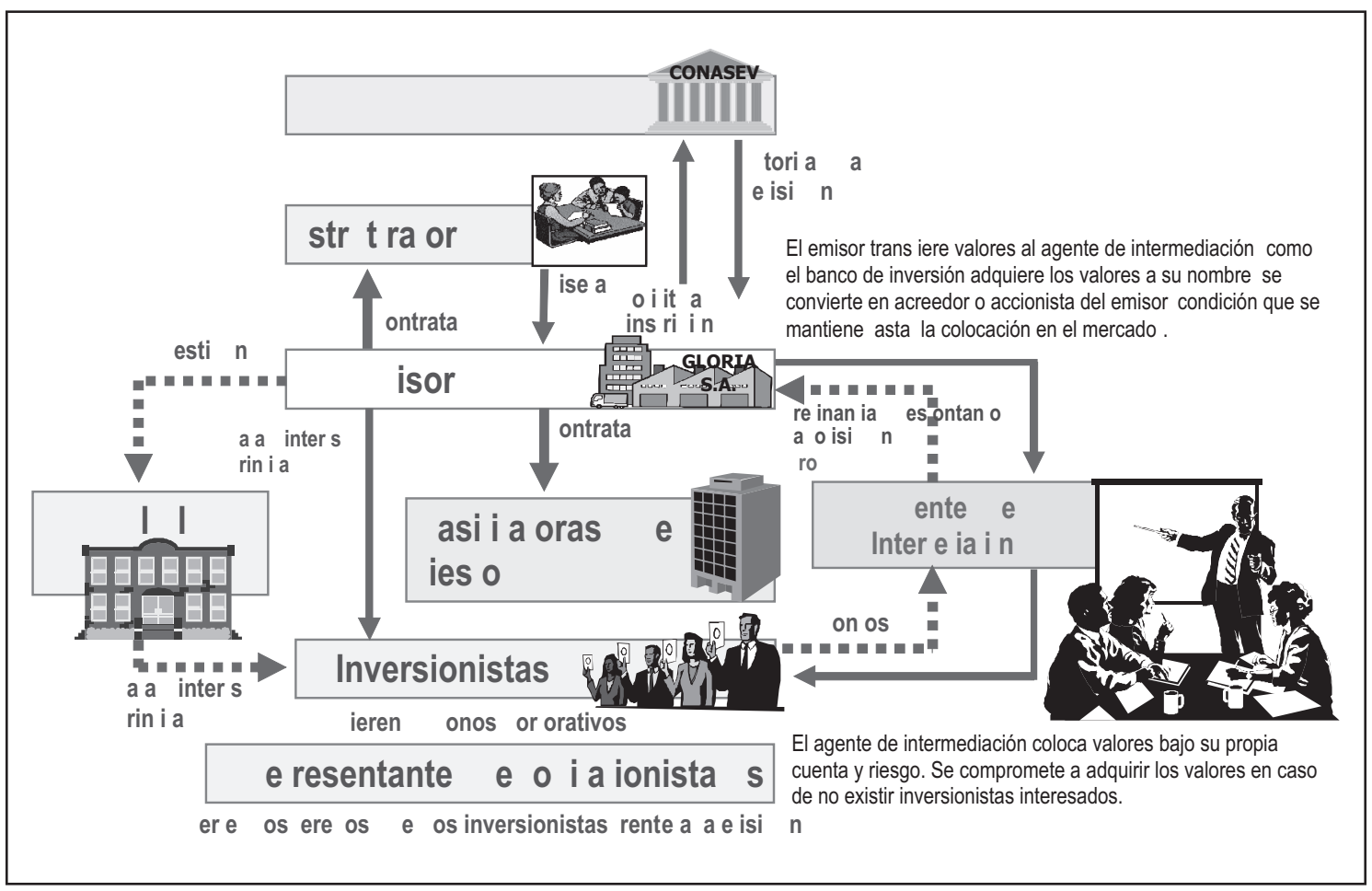

33 En nuestro país, los principales demandantes de bonos corporativos son los inversionistas institucionales como las AFP y las empresas de seguros.

34 Luego de que los bonos corporativos fueron colocados en el mercado, la empresa emisora debe pagar en forma periódica (trimestral, semestral, anual) los cupones (intereses) y al vencimiento, devolver el valor nominal del bono. En caso de incumplir con los pagos establecidos, el representante de los obligacionistas es el llamado a cautelar los intereses de estos ante cualquier incumplimiento por parte del emisor. CAVALI ICLV se encarga de recibir los valores del vendedor y el dinero del comprador, y entregar los valores al comprador y el dinero al vendedor. 
Finalmente, se debe precisar que en la colocación en firme, la oferta que debe efectuar el agente de intermediación puede ser abierta a todo tipo de sucriptor o bien puede pactarse que la misma esté limitada a un determinado segmento de inversionistas que reúnan las características deseadas por el emisor. Este tipo de oferta restringida se presenta especialmente en el caso que la empresa emisora desea que sus futuros accionistas reúnan ciertas condiciones, como el no ser sus competidores.

\section{TIPOS DE GARANTÍAS EN UNA EMISIÓN DE BONOS CORPORATIVOS}

El artículo 304 de la LGS establece expresamente que la sociedad puede emitir series numeradas de obligaciones que reconozcan o creen una deuda a favor de sus titulares. Una misma emisión de obligaciones puede realizarse en una o más etapas o en una o más series, si así lo acuerda la junta de accionistas o de socios, según el caso.

Asimismo, el artículo 305 de la LGS es claro al considerar que el importe total de las obligaciones, a la fecha de emisión, no podrá ser superior al patrimonio neto de la sociedad, con las siguientes excepciones:

1. Que se haya otorgado garantía específi$\mathrm{ca}^{35} ; \mathrm{o}$

2. Que la operación se realice para solventar el precio de bienes cuya adquisición o construcción hubiese contratado de antemano la sociedad; o

3. En los casos especiales que la ley lo permita.

Por otro lado, el artículo 307 de la LGS establece que las garantías específicas pueden ser:

1. Derechos reales de garantía $a^{36}$;

2. Fianza solidaria, emitida por entidades del sistema financiero nacional, compañías de seguros nacionales o extranjeras o bancos extranjeros.

Independientemente de las garantías mencionadas, los obligacionistas pueden hacer efectivos sus créditos sobre los demás bienes y derechos de la sociedad emisora o del patrimonio de los socios, si la forma societaria lo permite.

Por su parte, la Ley del Mercado de Valores, contempla el tema de las garantías de los bonos en el Título IV: Valores Mobiliarios, Capítulo II: Bonos. Al respecto, considera en el artículo 90 que, en la emisión, además de las garantías contempladas en la Ley de Sociedades, podrá constituirse carta fianza bancaria, depósito bancario, certificado bancario en moneda extranjera depositado en una institución financiera del país, póliza de caución de empresas de seguros y otras que se establezcan mediante disposiciones de carácter general.

Para la inscripción o registro de estas garantías, no es necesario individualizar a los obligacionistas y basta que se consigne el nombre del representante de estos. El custo-

35 Con relación a las garantías específicas Guillermo Ferrero y Rafael Boisset en El Contrato de Emisión y Suscripción de Obligaciones, Tratado de Derecho Mercantil Tomo III, expresan su desacuerdo con la obligación legal impuesta en el emisor de tener que constituir garantías específicas cuando el monto de la emisión sobrepase su patrimonio neto. Por ello, comparten la posición de Elías Laroza quien señala que "Sólo dentro del marco de una oferta pública de obligaciones (...). Puede afirmarse que existe una asimetría de la información, que supone que los administradores y los inversionistas tienen un acceso desigual al conocimiento de la situación real de la empresa y que por ende, requieren de garantías específicas impuestas por el Estado sobre el emisor en respaldo de los intereses de los obligacionistas".

36 Los Derechos Reales constituye una relación jurídica entre un sujeto y un objeto existente. Solo pueden ser creados por ley y pueden ejercerse contra todo poseedor. Para que tengan efectos frente a terceros los contratos y actos concernientes a derechos reales, estos deben constar en instrumento y registro público, según corresponda. Nuestro Código Civil contempla como derechos reales de garantía: la garantía mobiliaria, anticresis, hipoteca, derecho de retención. 
dio o depositario de las garantías, en su caso, no podrá tener vinculación con el emisor.

\section{EJECUCIÓN DE GARANTÍAS ESPECÍFICAS EN LA EMISIÓN DE BONOS DE BONOS CORPORATIVOS}

El artículo 327 de la LGS establece que antes de ejecutar las garantías específicas de la emisión, si se produce demora de la sociedad emisora en el pago de los intereses o del principal, el Representante de los Obligacionistas deberá informar a la asamblea general de obligacionistas, salvo que por la naturaleza de la garantía o por las circunstancias, requiera ejecutarlas en forma inmediata ${ }^{37}$.

Asimismo, el artículo 328 de la LGS considera que si se ha producido la demora en el pago de los intereses o del principal por parte de la sociedad emisora, cualquier obligacionista puede pedir al Representante de los Obligacionistas la correspondiente interposición de la demanda en proceso ejecutivo. Si el Representante de los Obligacionistas no interpone la demanda dentro del plazo de 30 días, cualquier obligacionista puede ejecutar individualmente las garantías, en beneficio de todos los obligacionistas impagos.

\section{EXTINCIÓN DELBONO CORPORATIVO}

\section{Rescate de los bonos}

El rescate de los bonos se refiere al pago anticipado, previo acuerdo con los obligacionistas. El artículo 330 de la LGS enumera las formas mediante las cuales, el emisor puede retirar de circulación o rescatar los bonos emitidos, a efectos de amortizarlos. Las formas previstas en este artículo son:

1. Por pago anticipado, de conformidad con los términos de la escritura pública de emisión.

2. Por oferta dirigida a todos los obligacionistas o a aquellos de una determinada serie.

3. En cumplimiento de convenios celebrados con el sindicato de obligacionistas.

4. Por adquisición en bolsa.

5. Por conversión en acciones, de acuerdo con los titulares de las obligaciones o de conformidad con la escritura pública de emisión.

Por su parte el artículo 89 de la LMV dispone que si en la oferta pública se hubiere previsto el rescate anticipado de los bonos, el procedimiento debe proveer un trato equitativo en esa materia para todos los obligacionistas.

\section{Vencimiento del plazo}

El vencimiento del plazo es la fecha en que se hace exigible la obligación (el bono), facultando al acreedor para exigir su cumplimiento o pago. Cuando se vence el plazo de vigencia de las obligaciones, debe redimirse el valor, es decir, debe pagarse su valor nominal y los intereses que pudieran corresponder.

El artículo 329 de la LGS establece que la sociedad emisora debe satisfacer el importe de las obligaciones en los plazos convenidos, con las primas y ventajas que se hubiesen estipulado en la escritura pública de emisión.

Asimismo, está obligada a celebrar los sorteos periódicos, dentro de los plazos y en

37 Al respecto, es importante lo establecido por el artículo 309 de la LGS, el cual considera que la fecha de cada emisión y series de obligaciones de un mismo emisor, determinará la prelación entre ellas, salvo que ella sea expresamente pactada a favor de alguna emisión o serie en particular, en cuyo caso será necesario que las asambleas de obligacionistas de las emisiones o series precedentes presten su consentimiento. 
la forma prevista en la escritura pública de emisión, con intervención del representante de los obligacionistas y en presencia de notario, quien extenderá el acta correspondiente.

El cumplimiento de estas obligaciones determina la caducidad del plazo de la emisión y autoriza a los obligacionistas a reclamar el reembolso de las obligaciones y de los intereses.

\section{COSTOS DE EMISIÓN DE UNA OFERTA PÚBLICA PRIMARIA DE BONOS CORPORATIVOS ${ }^{38}$}

Los costos de emisión son aquellos en los que el Agente Deficitario incurre para poder efectuar una Oferta Pública Primaria (OPP) de bonos sin considerar la tasa de rendimiento ofrecida a los inversionistas (tasa cupón). Incluyen los gastos de estructuración, inscripción, clasificación, colocación, entre otros. Para determinar los costos de emisión de bonos corporativos en el mercado peruano de capitales es necesario establecer algunos supuestos.

\begin{tabular}{|c|c|c|}
\hline $\begin{array}{c}\text { Valor } \\
\text { mobiliario }\end{array}$ & $\begin{array}{c}\text { Bono } \\
\text { corporativo }\end{array}$ & $\begin{array}{c}\text { Tasa } \\
\text { Porcentual }\end{array}$ \\
\hline Plazo & 5 años & \\
\hline Moneda & Dólares Americanos & \\
\hline \multirow{7}{*}{ Supuestos } & $\begin{array}{l}\text { Se aplica una tasa de descuento promedio } \\
\text { de las empresas del Perú, en dólares }\end{array}$ & \\
\hline & $\mathrm{TD}=\mathrm{rf}+\mathrm{b}(\text { prima de riesgo })^{1}$ & \\
\hline & $\mathrm{rf}=$ tasa libre de riesgo & $4.50 \%$ \\
\hline & $\mathrm{b}=$ beta del mercado $=1$ & \\
\hline & $\begin{array}{l}\text { Prima de riesgo para Perú = la obtenida } \\
\text { del trabajo elaborado por Javier Estrada } \\
\text { (Prof. Dpto. de Finanzas de IESE - Escue- } \\
\text { la de Negocios de Barcelona, España). }\end{array}$ & $18.67 \%$ \\
\hline & $\begin{array}{l}\text { TD = Tasa de Descuento Promedio para } \\
\text { Perú }\end{array}$ & $23.17 \%$ \\
\hline & Monto de la Emisión & $\$ 10,000,000.00$ \\
\hline
\end{tabular}

El cálculo de los costos de emisión de una oferta pública primaria de bonos corporativos se efectúa en las siguientes tablas:

\begin{tabular}{|c|c|c|c|c|c|c|c|}
\hline \multicolumn{8}{|c|}{ 1. ${ }^{\text {ra }}$ etapa: Preparación de la emisión } \\
\hline & & Única Vez & Año 1 & Año 2 & Año 3 & Año 4 & Año 5 \\
\hline Estructuración (0.85\%) & 0.0085 & $\$ 85,000.00$ & & & & & \\
\hline Derechos notariales & & $\$ 1,000.00$ & & & & & \\
\hline Asesoría legal (0.35\%) & 0.0035 & $\$ 35,000.00$ & & & & & \\
\hline $\begin{array}{l}\text { Elaboración del prospecto marco y } \\
\text { contrato de emisión }\end{array}$ & $\begin{array}{l}\text { (100 unidades) } \\
\text { por emisión }\end{array}$ & $\$ 1,500.00$ & & & & & \\
\hline Roadshow $^{2}$ & & $\$ 2,000.00$ & & & & & \\
\hline Sub total a valor presente & & $\$ 124,500.00$ & & & & & \\
\hline
\end{tabular}

38 Los datos para la determinación de los costos de emisión de una Oferta Pública Primaria de Bonos Corporativos se obtuvieron de los Anuarios Estadísticos de CONASEV. Asimismo, los cálculos se realizaron utilizando Hoja de Cálculo. 


\begin{tabular}{|c|c|c|c|c|c|c|c|}
\hline \multicolumn{8}{|c|}{ 2. ${ }^{a}$ etapa: Oferta Pública Primaria de Bonos Corporativos (OPPBC) } \\
\hline & & Única vez & Año 1 & Año 2 & Año 3 & Año 4 & Año 5 \\
\hline $\begin{array}{l}\text { Clasificación de riesgo } \\
(2 \text { empresas })^{3}\end{array}$ & $\$ 12,000.00$ & & $\$ 24,000.00$ & $\$ 24,000.00$ & $\$ 24,000.00$ & $\$ 24,000.00$ & $\$ 24,000.00$ \\
\hline $\begin{array}{l}\text { Valor presente } \\
\text { (clasificación de riesgo) }^{4}\end{array}$ & & & $\$ 67,042.90$ & & & & \\
\hline $\begin{array}{l}\text { Registro e inscripción } \\
\text { (CONASEV) }\end{array}$ & (1 UIT) & $\$ 1,000.00$ & & & & & \\
\hline Inscripción Cavali & & $\$ 100.00$ & & & & & \\
\hline $\begin{array}{l}\text { Inscripción BVL } \\
(0.0375 \%)\end{array}$ & 0.000375 & $\$ 3,750.00$ & & & & & \\
\hline $\begin{array}{l}\text { Actualización reg. públicos contrato } \\
\text { de emisión complementario }\end{array}$ & Por emisión & $\$ 500.00$ & & & & & \\
\hline $\begin{array}{l}\text { Actualización e impresión del } \\
\text { prospecto marco complementario }\end{array}$ & $\begin{array}{l}\text { (100 unidades }) \\
\text { por emisión }\end{array}$ & $\$ 600.00$ & & & & & \\
\hline $\begin{array}{l}\text { Publicación diario oficial El peruano } \\
\text { y diario de mayor circulación }\end{array}$ & $\begin{array}{l}\text { El Peruano }(\$ 400) \\
\text { y Gestión }(\$ 1000)\end{array}$ & $\$ 1,400.00$ & & & & & \\
\hline $\begin{array}{l}\text { Colocación en firme } \\
(0.15 \%)\end{array}$ & 0.00150 & $\$ 15,000.00$ & & & & & \\
\hline Sub total a valor presente & & $\$ 89,392.90$ & & & & & \\
\hline
\end{tabular}

\begin{tabular}{|l|c|c|c|c|c|c|c|}
\hline \multicolumn{7}{|c|}{ 3. ${ }^{2}$ etapa: Mantenimiento de la Oferta Pública Primaria de Bonos Corporativos } \\
\hline & & Año 0 & Año 1 & Año 2 & Año 3 & Año 4 & Año 5 \\
\hline $\begin{array}{l}\text { Comisión representante de } \\
\text { obligacionistas (0.035\%) }\end{array}$ & 0.00035 & & $\$ 3,500.00$ & $\$ 3,500.00$ & $\$ 3,500.00$ & $\$ 3,500.00$ & $\$ 3,500.00$ \\
\hline $\begin{array}{l}\text { Derechos Cavali } \\
(0.010 \%)\end{array}$ & 0.00010 & & $\$ 1,000.00$ & $\$ 1,000.00$ & $\$ 1,000.00$ & $\$ 1,000.00$ & $\$ 1,000.00$ \\
\hline $\begin{array}{l}\text { Derechos cotización BVL } \\
(0.020 \%)\end{array}$ & 0.00020 & & $\$ 2,000.00$ & $\$ 2,000.00$ & $\$ 2,000.00$ & $\$ 2,000.00$ & $\$ 2,000.00$ \\
\hline $\begin{array}{l}\text { Derechos cotización CONASEV } \\
(0.035 \%)\end{array}$ & 0.00035 & & $\$ 3,500.00$ & $\$ 3,500.00$ & $\$ 3,500.00$ & $\$ 3,500.00$ & $\$ 3,500.00$ \\
\hline Sub total & & & $\$ 10,000.00$ & $\$ 10,000.00$ & $\$ 10,000.00$ & $\$ 10,000.00$ & $\$ 10,000.00$ \\
\hline Sub total a valor presente & & $\mathbf{2 7 , 9 3 4 . 5 4}$ & & & & & \\
\hline
\end{tabular}


Por lo tanto, si sumamos los datos obtenidos en los sub totales a valor presente de cada etapa se tiene que el costo de emisión en unidades monetarias de una oferta pública primaria de bonos corporativos es de US\$ 241,827.43 dólares, el mismo que representa el $2.42 \%$ del monto total de la emisión (US\$ 10 millones de dólares).

\begin{tabular}{|l|c|c|}
\hline \multicolumn{3}{|c|}{ Total costos de emisión de la oferta pública primaria } \\
de bonos corporativos
\end{tabular}

El 2.42\% representa el costo de la emisión expresado en porcentaje del total de la emisión, sin embargo, este dato también puede expresarse en términos anuales (en promedio). Es así que el equivalente al $2.42 \%$ (costo total durante los cinco años de la emisión del bono corporativo) es el $0.48 \%$ promedio anual, según detalle siguiente:

\begin{tabular}{|l|c|c|}
\hline \multicolumn{3}{|c|}{ Tasa de interés efectiva anual (TEA) } \\
\hline Costo de la emisión & CE & $2.42 \%$ \\
\hline$(1+\mathrm{CE})$ & & 1.024182743 \\
\hline$(1+\mathrm{CE})^{\wedge} 1 / 5$ & 0.2 & 1.004790432 \\
\hline TEA & {$\left[(1+\mathrm{CE})^{\wedge} 1 / 5-1\right]^{*} 100$} & $0.48 \%$ \\
\hline
\end{tabular}

\begin{tabular}{|l|c|c|c|c|c|c|c|}
\hline \multicolumn{7}{|c|}{ Cálculo del costo de emitir bonos corporativos (expresado en \%) } \\
\hline & & Año 0 & Año 1 & Año 2 & Año 3 & Año 4 & Año 5 \\
\hline Valor de mercado & P & $\$ 10,000,000.00$ & & & & & \\
\hline $\begin{array}{l}\text { Valor presente de los costos de } \\
\text { emisión }\end{array}$ & G & $\$ 241,827.43$ & & & & & \\
\hline C = tasa cupón del bono (anual) & $8.50 \%$ & & & & & & \\
\hline Cupones & Anual & & $850,000.00$ & $850,000.00$ & $850,000.00$ & $850,000.00$ & $10,850,000.00$ \\
\hline Sub total & & $-\$ 9,758,172.57$ & $850,000.00$ & $850,000.00$ & $850,000.00$ & $850,000.00$ & $10,850,000.00$ \\
\hline Costo de la deuda & en \% anual & $9.1237 \%$ & & & & & \\
\hline
\end{tabular}

Según estos resultados, en las condiciones actuales de nuestro mercado de valores, el costo de emisión de bonos corporativos mediante Oferta Pública Primaria es de $9.1237 \%$ promedio anual.

\section{COLOCACIÓN ANUAL DE BONOS CORPORATIVOS EN EL PERÚ}

En el cuadro N.o 2, se puede apreciar las ofertas públicas primarias de bonos corporativos realizadas durante los años 20032008. Se observa que son 48 las empresas que colocaron bonos corporativos en nuestro país, haciendo un total de 131 emisiones, de las cuales, 124 fueron realizadas por grandes empresas. El menor monto colocado en soles fue de S/. 17 millones por la empresa Financiera Cordillera S.A. Asimismo, el menor monto colocado en dólares fue de US\$ 3 millones por Gloria S.A. en el año 2003 y por la Compañía Industrial Textil Credisa - Trutex S.A.A. durante los años 2005 y 2006. Por otro lado, el mayor monto colocado durante el período 2003-2008 fue de 596 millones de soles por Telefónica del Perú. 
Cuadro N.o 2. Colocación Anual de Bonos Corporativos por emisor y tipo de monedas 20032008 (En miles de unidades monetarias).

\begin{tabular}{|c|c|c|c|c|c|c|c|c|c|c|c|c|}
\hline \multirow{2}{*}{ EMISOR } & \multicolumn{2}{|c|}{2003} & \multicolumn{2}{|c|}{2004} & \multicolumn{2}{|c|}{2005} & \multicolumn{2}{|c|}{2006} & \multicolumn{2}{|c|}{2007} & \multicolumn{2}{|c|}{2008} \\
\hline & US\$ & $\mathbf{S} /$. & US\$ & $\mathbf{S} /$. & US\$ & $\mathbf{S} /$. & US\$ & $\mathbf{S} /$. & US\$ & $\mathbf{S} /$. & US\$ & $\mathbf{S} /$. \\
\hline - B. CORPORATIVOS & 395,847 & $1,169,935$ & 430,551 & 871,160 & 296,098 & $1,158,295$ & 478,000 & $2,093,030$ & 192,507 & $2,246,215$ & 85,229 & $1,823,040$ \\
\hline Alicorp S.A.A. & 5,000 & & 5,000 & - & - & - & - & - & & 63,700 & - & \\
\hline Banco de Crédito del Perú & & - & - & 20,000 & - & 120,000 & - & 151,000 & - & 150,000 & - & 410,000 \\
\hline Banco Financiero del Perú & - & - & - & 100,800 & - & - & & - & & - & 5,650 & - \\
\hline Banco Ripley & & & & & & & & & & & - & 100,050 \\
\hline BBVA Banco Continental & & & 48,840 & - & - & 70,000 & . & 130,000 & 48,502 & 40,000 & - & 60,000 \\
\hline Cementos Lima S.A. & - & . & - & . & . & - & . & - & . & 160,000 & - & 60,000 \\
\hline Cementos Pacasmayo S.A.A. & 80,000 & - & - & - & & - & & - & & - & & - \\
\hline Citibank del Perú S.A. & & & & - & - & - & 10,000 & 100,000 & - & - & - & \\
\hline Compañía Industrial Textil Credisa - Trutex S.A.A. & & . & 4,000 & . & 3,000 & . & 3,000 & - & . & . & . & \\
\hline Compañía Minera Atacocha S.A. & . & . & 10,000 & . & . & . & . & - & . & . & . & . \\
\hline Consorcio Transmantaro S.A. & 20,000 & - & . & - & - & - & - & - & - & . & - & - \\
\hline Corporación Andina de Fomento - CAF & - & - & - & - & . & - & . & 248,400 & - & . & - & - \\
\hline Corporación Financiera de Desarrollo -COFIDE & . & - & . & - & . & 50,000 & . & 193,600 & . & 60,000 & - & 36,870 \\
\hline Corporación Financiera Internacional - IFC & - & - & - & 50,000 & & 100,000 & & - & - & . & & - \\
\hline Corporación José R. Lindley & & & & & & & & & & & - & 138,410 \\
\hline Duke Energy Egenor S. en C.por A. & 40,000 & & . & . & 75,000 & 113,890 & . & . & . & . & . & \\
\hline Edegel S.A.A. & - & 250,000 & 20,000 & 50,000 & 20,000 & 153,070 & . & 80,000 & 8,000 & 195,000 & 19,720 & 28,300 \\
\hline Edelnor S.A.A. & - & 40,000 & & 150,000 & & 60,000 & - & 168,450 & - & 150,000 & - & 198,465 \\
\hline Edyficar & - & - & - & - & - & - & - & - & - & 25,000 & - & 30,000 \\
\hline Electroandes S.A. & 70,000 & 104,460 & & & & - & - & - & & - & - & . \\
\hline Empresa de Generación Eléctrica Cahua S.A. & - & - & - & - & 32,000 & - & - & - & - & - & - & - \\
\hline Enersur & - & - & - & - & - & - & - & - & - & 120,700 & 10,000 & 84,105 \\
\hline Ferreyros S.A.A. & 15,000 & - & 15,000 & - & 25,000 & - & 10,000 & - & 40,000 & - & 33,000 & - \\
\hline Financiera Cordillera S.A. & . & - & - & - & 5,000 & 17,105 & 5,000 & 48,390 & - & . & . & . \\
\hline Gloria S.A. & 3,000 & 52,125 & . & 35,000 & - & 122,000 & & 40,000 & & 240,000 & - & - \\
\hline Graña y Montero S.A.A & - & - & 7,711 & - & - & - & - & - & & - & - & - \\
\hline Luz del Sur S.A.A. & . & 173,970 & & 138,760 & & 85,020 & . & 167,060 & - & 154,050 & & 70,800 \\
\hline Mibanco, Banco de la Microempresa S.A. & . & 30,000 & . & - & - & . & - & - & 10,000 & 60,000 & - & 30,000 \\
\hline Minera Barrick Misquichilca S.A. & - & - & - & - & 50,000 & - & 50,000 & - & - & - & - & - \\
\hline Minera Yanacocha S.R.L. & - & - & - & - & - & - & 100,000 & - & & - & - & \\
\hline Palmas del Espino & . & . & - & . & . & . & & - & & 88,500 & 16,859 & . \\
\hline Pluspetrol Camisea S.A. & & & - & - & - & - & 150,000 & - & - & - & . & \\
\hline Pluspetrol Norte S.A. & & & 50,000 & - & - & - & - & - & - & - & - & \\
\hline Quimpac S.A. & & - & 20,000 & . & - & - & - & - & - & - & - & - \\
\hline Ransa Comercial S.A. & - & - & - & - & - & - & - & - & 7,000 & - & - & \\
\hline Red de Energia del Perú S.A. & 30,000 & 69,540 & 50,000 & - & - & - & - & - & 60,000 & - & - & - \\
\hline Saga Falabella S.A. & & & & - & - & - & & 90,000 & & 25,000 & - & - \\
\hline Scotiabank Perú & - & & & - & & - & & - & - & 56,660 & & 250,000 \\
\hline Sociedad Minera Cerro Verde S.A.A. & . & . & . & - & . & - & 90,000 & . & . & . & . & . \\
\hline Solución Financiera de Crédito del Perú S.A. & . & 55,000 & - & 30,000 & . & - & . & - & - & - & - & - \\
\hline Southern Perú Copper Corp. Suc. Perú & 50,000 & - & . & . & . & . & . & - & . & . & . & . \\
\hline Supermercados Peruanos S.A. & & & & & & - & . & . & 19,005 & 21,540 & & \\
\hline Telefónica del Perú S.A.A. & 57,847 & 273,190 & - & 60,000 & - & 238,250 & - & 404,130 & - & 596,065 & - & 276,040 \\
\hline Telefónica Móviles S.A. & - & - & - & - & & - & 60,000 & 272,000 & - & . & & - \\
\hline Transportadora de Gas del Perú S.A. & . & - & 200,000 & 236,600 & 71,098 & 28,960 & . & - & - & - & - & - \\
\hline Unión de Cervecerías Peruanas Backus y Johnston S.A.A. & 25,000 & 87,050 & - & - & . & - & . & . & - & . & . & . \\
\hline Universidad San Martín de Porres & . & . & . & - & 15,000 & - & . & - & - & - & - & - \\
\hline Yura S.A. & - & 34,600 & & & & - & & - & - & 40,000 & & 50,000 \\
\hline
\end{tabular}

Fuente: CONASEV - Memoria Anual 2008 


\section{TAMAÑO DE LAS OFERTAS PÚBLICAS PRIMARIAS DE BONOS CORPORATIVOS}

La importancia relativa del mercado de bonos corporativos se puede medir relacionando las ofertas públicas primarias de bonos corporativos (OPPBC) y el Producto Bruto Interno (PBI). Por ejemplo, en el cuadro siguiente sobre el caso peruano, se puede apreciar la evolución tanto de las ofertas públicas primarias de bonos corporativos como del Producto Bruto Interno durante los años 2003-2008.

Cuadro N.o 3. Ofertas públicas primarias de bonos corporativos vs. Producto Bruto Interno 2003- 2008 (Expresado en nuevos soles).

\begin{tabular}{|l|c|c|c|c|c|c|}
\hline & $\mathbf{2 0 0 3}$ & $\mathbf{2 0 0 4}$ & $\mathbf{2 0 0 5}$ & $\mathbf{2 0 0 6}$ & $\mathbf{2 0 0 7}$ & $\mathbf{2 0 0 8}$ \\
\hline OPРBC & 2.357 .476 .000 & 2.162 .814 .469 & 2.046 .589 .000 & 3.527 .030 .000 & 2.823 .736 .000 & 2.078 .727 .000 \\
\hline PBI & 132.545 .000 .000 & 139.141 .000 .000 & 148.640 .000 .000 & 160.145 .000 .000 & 174.329 .000 .000 & 191.479 .000 .000 \\
\hline ОРРВС/РBI & $1,92 \%$ & $1,68 \%$ & $1,44 \%$ & $2,28 \%$ & $1,63 \%$ & $1,08 \%$ \\
\hline
\end{tabular}

Fuente : Banco Central de Reserva del Perú - Memoria Anual 2008.

CONASEV - Memoria Anual 2008.

En la gráfica siguiente, se puede observar que en el año 2006, las ofertas públicas primarias de bonos corporativos (OPPBC) representaron el $2.28 \%$ del Producto Bruto Interno (PBI) sin embargo, para el año 2008, este indicador experimentó una caída considerable, situándose en $1.08 \%$, lo cual demuestra la limitada utilización de las ofertas públicas primarias de bonos corporativos como alternativa de financiamiento empresarial en el Perú.

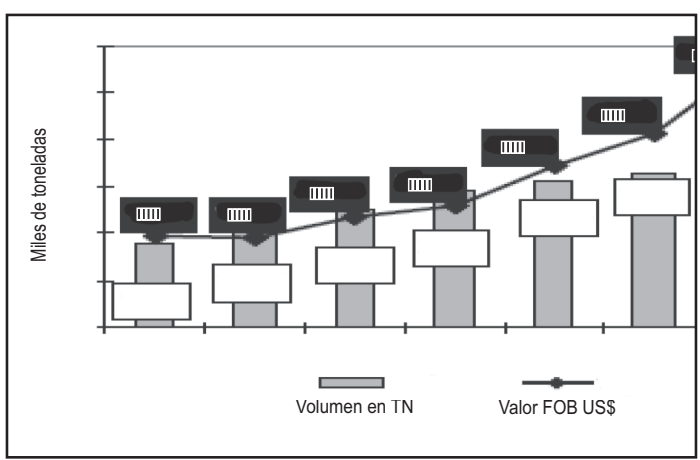

\section{RANKING DE LAS EMPRESAS QUE COLOCARON BONOS CORPORATIVOS EN EL PERÚ}

En el cuadro N. 4 se puede apreciar el ranking de cada una de las empresas que emitieron bonos corporativos en nuestro mercado, según la la publicación Perú: The Top 10,000 companies 2008. Esta clasificación se basa en los ingresos totales según el ejercicio 2007.

$\mathrm{Al}$ respecto, se debe precisar que la empresa Southern Perú Copper Corp. Suc Perú, realizó una emisión de bonos corporativos en el año 2003 y fue considerada la mejor empresa en nuestro país en el año 2007. Asimismo, 04 de las empresas emisoras de bonos corporativos se encuentran dentro de las 10 mejores empresas del Perú y 25 dentro de las 100 mejores empresas del Perú. Con 
relación a los ingresos totales, existe una diferencia marcada entre la primera y segunda mejor empresa del ranking 2007, es decir, entre Southern Perú Copper Corp. Suc. Perú y Sociedad Minera Cerro Verde S.A.A, respectivamente.

Cuadro N.o 4. Ranking 2007 de las empresas emisoras de bonos corporativos en el Perú.

\begin{tabular}{|c|c|c|}
\hline Ranking 2007 & Compañías emisoras de bonos corporativos & Ingresos 2007 (en miles de soles) \\
\hline 1 & Southern Perú Copper Corp. Suc. Perú & $9,990,328$ \\
\hline 5 & Sociedad Minera Cerro Verde S.A.A. & $5,615,175$ \\
\hline 7 & Telefónica del Perú S.A.A. & $3,953,672$ \\
\hline 9 & Banco de Crédito del Perú & $3,765,460$ \\
\hline 12 & Minera Yanacocha S.R.L. & $3,593,800$ \\
\hline 13 & Minera Barrick Misquichilca S.A. & $3,443,055$ \\
\hline 16 & Telefónica Móviles S.A. & $2,580,610$ \\
\hline 18 & Alicorp S.A.A. & $2,505,425$ \\
\hline 20 & BBVA Banco Continental & $2,391,455$ \\
\hline 21 & Pluspetrol Norte S.A. & $2,358,171$ \\
\hline 23 & Unión de Cervecerías Peruanas Backus y Johnston S.A.A. & $2,100,910$ \\
\hline 25 & Gloria S.A. & $1,959,724$ \\
\hline 27 & Scotiabank Perú & $1,835,642$ \\
\hline 30 & Ferreyros S.A.A. & $1,655,265$ \\
\hline 35 & Luz del Sur S.A.A. & $1,368,437$ \\
\hline 36 & Saga Falabella S.A. & $1,324,892$ \\
\hline 37 & Edelnor S.A.A. & $1,323,384$ \\
\hline 40 & Supermercados Peruanos S.A. & $1,313,389$ \\
\hline 52 & Edegel S.A.A. & $1,058,106$ \\
\hline 58 & Corporación José R. Lindley & $1,023,229$ \\
\hline 68 & Cementos Lima S.A. & 864,140 \\
\hline 69 & Enersur & 858,826 \\
\hline 76 & Pluspetrol Camisea S.A. & 734,570 \\
\hline 89 & Transportadora de Gas del Perú S.A. & 580,595 \\
\hline 95 & Compañía Minera Atacocha S.A. & 550,544 \\
\hline 101 & Citibank del Perú S.A. & 489,590 \\
\hline 111 & Duke Energy Egenor S. en C.por A. & 450,705 \\
\hline 121 & Cementos Pacasmayo S.A.A. & 444,410 \\
\hline 131 & Mibanco, Banco de la Microempresa S.A. & 417,548 \\
\hline 143 & Banco Ripley & 378,040 \\
\hline 145 & Yura S.A. & 373,200 \\
\hline 151 & Quimpac S.A. & 355,349 \\
\hline 186 & Banco Financiero del Perú & 302,294 \\
\hline 198 & Universidad San Martín de Porres & 282,262 \\
\hline 200 & Compañía Industrial Textil Credisa - Trutex S.A.A. & 281,345 \\
\hline 226 & Ransa Comercial S.A. & 247,533 \\
\hline 264 & Red de Energía del Perú S.A. & 221,324 \\
\hline 276 & Corporación Financiera de Desarrollo -COFIDE & 209,588 \\
\hline 346 & Electroandes S.A. & 169,010 \\
\hline 510 & Edyficar & 113,929 \\
\hline 617 & Consorcio Transmantaro S.A. & 87,906 \\
\hline 625 & Empresa de Generación Eléctrica Cahua S.A. & 85,387 \\
\hline 909 & Palmas del Espino & 83,549 \\
\hline 1661 & Graña y Montero S.A.A & 81,249 \\
\hline 5496 & Solución Financiera de Crédito del Perú S.A. & 79,548 \\
\hline
\end{tabular}

Fuente: Publicación Peru The Top 10,000 Companies 2008. 


\section{CLASIFICACIÓN DE LAS EMPRESAS QUE EMITIERON BONOS CORPORATIVOS EN EL PERÚ}

\section{Clasificación según sus ingresos}

De las 48 empresas que emitieron bonos corporativos durante el período 2003-2008, solo cuatro son consideradas medianas empresas (Edyficar, Palmas del Espino, Graña y Montero S.A.A y Solución Financiera de Crédito del Perú S.A.) y el resto son grandes empresas.

Asimismo, existen 22 empresas que se encuentran retiradas del mercado, es decir, ya no realizaron ofertas públicas primarias de instrumentos financieros durante el período 2003-2008.

\section{Clasificación de las empresas por sectores}

En la gráfica siguiente, se puede apreciar la clasificación de las empresas, por sectores, que recurrieron al mercado primario de valores como alternativa de financiamiento a través de bonos corporativos.

Se observa, que de las 48 empresas que emitieron bonos corporativos durante el período 2003-2008, 09 empresas corresponden al sector de la industria manufacturera, 11 empresas a la intermediación financiera, 05 a la minería, 10 al sector de electricidad, gas y agua, 01 a la enseñanza y 01 a la construcción.

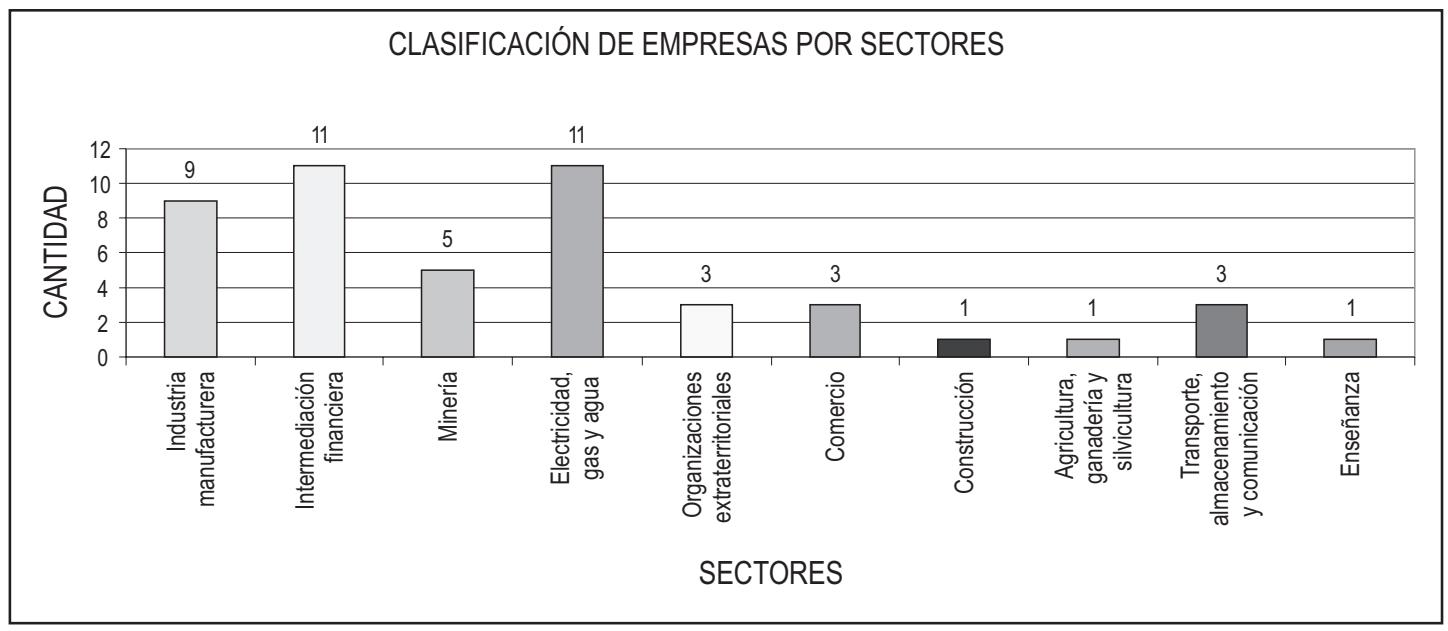

\section{CONCLUSIONES}

1. La principal limitación en el análisis de las ofertas públicas primarias de bonos corporativos en nuestro país es la dispersión de este tema en la legislación vigente: Ley de Títulos Valores, Ley General de Sociedades, Ley del Mercado de Valores y Ley General del Sistema Financiero y Sistema de Seguros y Orgánica de la Superintendencia de Banca y Seguros.
Cada una de ellas regula, en forma aislada, aspectos relacionados a las ofertas públicas primarias de bonos corporativos, lo cual conduce en cierta forma a duplicar esfuerzos y cargar costos innecesarios a los participantes de este mercado, específicamente a las empresas emisoras, que son la fuente del mercado primario de valores que da origen al mercado de capitales al generar nuevas ofertas de valores. 
2. El Mercado de Valores Peruano como alternativa de financiamiento, se caracterizó por un dinamismo creciente durante los años 2003-2008 en términos de Oferta Pública Primaria y por el reducido número de empresas emisoras que se incorporaron a este mercado. El instrumento más utlizado como alternativa de financiamiento fue la emisión de bonos corporativos. De las 48 empresas que colocaron ofertas públicas primarias de bonos corporativos, solo 04 son consideradas medianas empresas, las que emitieron bonos corporativos en siete oportunidades. Al mes de diciembre del año 2008, las colocaciones de ofertas públicas primarias fueron de US\$371,231 en dólares y S/. 2,961,280 en nuevos soles.

3. La existencia de algunos costos fijos durante el proceso de emisión de bonos corporativos tales como la clasificación de riesgo de la emisión, cuotas de mantenimiento a las entidades reguladoras y otros, así como de costos no recurrentes como es el caso las comisiones de estructuración y colocación, gastos de promoción, comisiones por "underwriting" y otros, hace que el costo total de esta alternativa de financiamiento varíe de manera importante en función del monto y del plazo de la emisión. Por ello, resulta muy importante colocar emisiones por montos lo suficientemente altos como para diluir los costos fijos del proceso y con plazos lo suficientemente largos como para absorber los costos no recurrentes relacionados con la preparación de la emisión. Según el análisis efectuado al mercado de ofertas públicas primarias de bonos corporativos, se determinó que para el caso peruano el costo de emisión es del $2,42 \%$ como porcentaje del monto colocado en dólares (en promedio US\$ 10 millones de dólares de emisión).

4. En el proceso de colocación de una oferta pública primaria de bonos corporativos existe asimetría de la información, debido a que los tenedores del bono (obligacionistas) y el emisor tienen acceso desigual al conocimiento de la situación económica y financiera de la empresa y consiguientemente, requieren garantías específicas sobre la empresa emisora, las mismas que se encuentran expresamente establecidas en la Ley General de Sociedades en respaldo de los intereses de los inversionistas que son los que arriesgan su dinero y se encuentran expuestos al riesgo de incumplimiento por parte del emisor de los bonos corporativos. El riesgo de incumplimiento en una oferta pública primaria de bonos corporativos es el riesgo que el emisor de los bonos corporativos no cumpla con la obligación o deuda contraída.

\section{REFERENCIAS BIBLIOGRÁFICAS}

1. Arias-Schreiber Pezet, Max; Gutiérrez, Walter. La técnica contractual. Tomo III, Editorial Gaceta Jurídica, Lima, 1997.

2. Beaumont Callirgos, Ricardo; Castellares Aguilar, Rolando. Comentarios a la nueva ley de títulos valores. Editorial Gaceta Jurídica, Lima, 2000.

3. Castellares, Rolando; Díaz, Enrique; Rocca, Lilian; Vargas, Julio. El ABC del mercado de capitales. Universidad San Ignacio de Loyola, 165 pp., Lima, 1998.

4. Comisión Nacional Supervisora de Empresas y Valores. Memorias 2003-2008.

5. Elías, Enrique. Derecho societario peruano. Editora Normas Legales S.A.C., 1019 pp., Trujillo, 1999. 
6. Farina, Juan M. Contratos comerciales modernos. 2. ${ }^{a}$ ed., Editorial Astrea, Buenos Aires, 830 pp., 1997.

7. Fernández Baca, Jorge, Teoría y política Monetaria, 1. ${ }^{\text {ra }}$ ed., Universidad del Pacífico, Lima, 2008.

8. Ferrero, Guillermo; Boisset, Rafael. "El contrato de emisión y suscripción de obligaciones". En Tratado de derecho mercantil. Tomo III, Gaceta Jurídica S.A., Lima, 2008.

9. García Kilroy, Catiana. Apuntes para la liquidación de valores. San José, Costa Rica, 1998.

10. Ley del Mercado de Valores. Decreto Legislativo N.o 861 (22/10/1996).

11. Ley de Títulos Valores. Ley N. 27287 (19/06/2000).

12. Ley General de Sociedades, Ley N. ${ }^{\circ}$ 26887 (09/12/1997).

13. Ley General del Sistema Financiero y del Sistema de Seguros y Orgánica de la Superintendencia de Banca y Seguros. Ley N.o 26702 (09/12/1996).

14. López, Rafael; Sousa, Lorenzo. Banca de inversión en el Perú. Publicaciones Universidad de Piura, 288 pp., Piura, 1996.

15. Ministerio de Economía y Finanzas. Resultado de consulta ciudadana: Acceso al financiamiento a través del mercado de valores; 116 pp., Lima, 23 de mayo de 2001.
16. Mochón Morcillo, Francisco; Isidro Aparicio, Rafael. Diccionario de términos financieros y de inversión. Editorial McGraw-Hill, 414 pp., España, 1995.

17. Montoya Manfredi, Ulises; Montoya Alberti, Ulises; Montoya Alberti, Hernando. Comentarios a la ley de títulos valores. Editora Jurídica Grijley, Lima, 2005.

18. Noriega Nairn, Fernando. La bolsa de valores, instituciones e instrumentos del mercado de valores peruano. $1 .^{\text {ra }}$ ed., Universidad de San Martín de Porres, 236 pp., Lima, 1998.

19. North C., Douglass. Instituciones, cambio institucional y desempeño económico. Primera edición en español, Editorial Fondo de Cultura Económica, 190 pp., México, 1993.

20. Perú: The Top 10,000 Companies, Las Top 10,000 del 2007; Perú Top Publications SAC., Lima, 2008.

21. Serra Puente-Arnao, Gerardo. El mercado de valores en el Perú. Editores Cultural Cusco S.A., Lima, 2002.

22. Texto Único Ordenado de la Ley del Mercado de Valores. Decreto Supremo N.o 093-2002-EF (15/06/2002). 